\title{
Comparative Efficiency of Some Indigenous Traps to Capture Rats in the Wheat Field of Bangladesh
}

\author{
A. T. M. Hasanuzzaman ${ }^{*}$, M. S. AlAM $^{2}$ \& M. M. Bazzaz ${ }^{3}$ \\ ${ }^{1 \& 2}$ Vertebrate Pest Division, Bangladesh Agricultural Research Institute, Gazipur, Bangladesh \\ ${ }^{3}$ Wheat Research Sub-station, BARI, Rajbari, Dinajpur, Bangladesh
}

\begin{abstract}
Comparative efficiency of some indigenous traps for capturing rodents was evaluated in the wheat fields of Dinajpur district of Bangladesh during August 2007 to May 2008. Five different types of traps such as, cage type live trap, box type live trap, wooden live trap, tin made snap trap and wooden snap trap were evaluated and five types of bait (bread, potato, coconut meat, dry fish and paddy grain) were used for trapping rodents. At grain filling and ripening stages of wheat, the cage type live trap was found most effective (44.11\% success) followed by tin made snap trap (30.73\% success), wooden snap trap (14.62\% success), box type live trap (10.41\% success) and wooden live trap (9.85\% success) using bread, dry fish, paddy grain, coconut and potato as bait. About 99 per cent of the trapped rats were identified as Badicota bengalensis and only 1 per cent was Mus terricolor. The descending order of preference of bait by B. bengalensis was: paddy grain> bread> dry fish> coconut> potato. A considerable number of shrew, Suncus murinus (12.72\% of total animal) was also captured all over the season.
\end{abstract}

Key words: Traps, rat capture, wheat field.

\section{INTRODUCTION}

Rats are serious problem in crop field of Bangladesh. Rat also damage buildings, households' goods and electrical wire etc. and also are potential threats to both human and animal health as vector of diseases (Wang, 1996). Rats are the serious pest of wheat crop throughout southern Asia causing damage from 3.5 to 12\% (Bindra and Sagar, 1968; Sood and Guraya, 1976; Ahmad, 1986). According to Ahmed et al. (1986) rat cause 5.7\% losses to deep water rice. Rats are major problem in the poultry sector too. They damage the floor of the farm by extensive burrowing and also attack the young birds (Roy et al, 1987). Burrowing rat hoards a large quantity of food in its burrows (Parrack, 1969; Roy, 1974).

In Bangladesh, rat control is traditionally based on the use of poison baits (rodenticides) and traps. Farmers commonly used zinc phosphide and lanirat (Bromadiolone) as poison bait, for rodent control. However, especially in rural areas there are several constraints for its use. Primarily, rodenticides are not affordable to the rural poor. Even, when rodenticides are widely available, due to farmers ignorance, inappropriate dose of rodenticide are used and bait shyness among the rat population is commonly seen. This shyness creates a serious problem in rodent control by

\footnotetext{
* Corresponding author: SO, Vertebrate Pest Division, BARI, Gazipur-1701, Mobile: 01711149837, E-mail: hasanbari@yahoo.com
}

(C) 2009 School of Agriculture and Rural Development, Bangladesh Open University, All rights reserved. 


\section{A. T. M. Hasanuzzaman et al.}

developing a resistant population. Changing chemical control techniques with trapping can solve this problem. On the other hand, by constant and indiscriminate use of anticoagulant rodenticides, rat can develop resistance on it (Buckle, 1999). Chemical methods are not ecologically sound for rat control. Indiscriminate use of poison creates serious health hazards to human beings and their pet animals and creates environment pollution.

Recently pest management strategies have emphasized on the ecologically sound method for rat control. Ecologically-sound rodent management provides the necessary platform for designing management strategies, which are environmentally safe (Singleton et al. 1999). Trapping rat is an age old method which is ecologically sound and environment friendly. Some scientists have shown that trapping can, under some circumstances, be an effective method of rodent management (Gebauer et al. 1992, Tobin et al. 1993, Ahmed et al. 1995). Different types of live and kill traps are commonly used for controlling rodents in Bangladesh. Although trapping is a common rodent control practice among the farmers of Bangladesh, details information about the efficiency of these traps in wheat field situation is yet unknown. The present study was conducted to evaluate the efficiency of different indigenous traps and to find out the best trap, which might be useful to the wheat farmers of Bangladesh.

\section{MATERIALS AND METHODS}

The experiment was conducted in the farmers' wheat field and wheat field of wheat research substation, Rajbari, Dinajpur during August 2007 to May 2008. Five different types of traps were used for capturing rats such as cage type live trap (Fig. 1), box type live trap (Fig. 2), wooden live trap (Fig. 3), tin made snap trap (Fig. 4) and wooden snap trap (Fig. 5). The experiment was laid out in Randomized Complete Block Design (RCBD) with 3 replications. Five bait materials were used for trapping rats and these were bread, potato, coconut, dry fish and paddy grain (un-husked). Each type of bait was used for all kinds of traps set at a time. The experiment was conducted for 1800 trap nights throughout the wheat season i.e., 990 trap nights at grain filling stage and 810 trap nights at ripening stage. When 1 trap was set for 1 night, it was considered as a 1 trap night. Equal numbers of trap nights were used for each type of trap. Only active burrows were used for setting the traps. The burrows with fresh soil at the opening including some symptoms of new activities were identified and marked as the "active burrows" having rats inside. One trap was set near the active burrow openings of one burrow system. So number of trap setting per night was depended upon the availability of active burrow system. The presence of rat inside the burrow was ensured by using tracking tiles. Capture of rat species was the measure of trap success. All the traps were set in the evening and the data were recorded in the following morning. Each trapped animal was examined and identified up to species level. Per cent trap success for each kind of trap and for each type of bait material was calculated. Data were analyzed by using MSTAT software for analysis of variance. Percentage data were arcsine transformed prior to analysis. Least Significance Difference (LSD) test was used to compare mean values. $X^{2}$-test was used to evaluate the different kinds of bait.

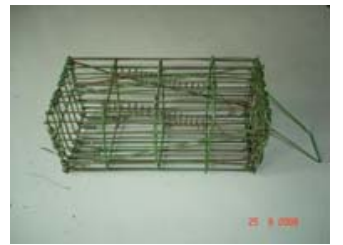

Fig. 1 = Cage type live trap made by iron net

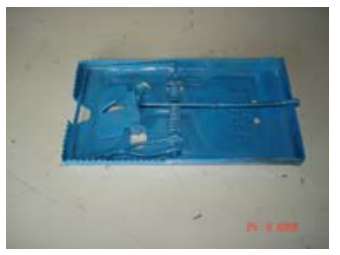

Fig.4 $=$ Tin made snap trap

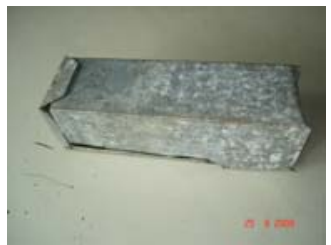

Fig.2 = Box type live trap made by tin

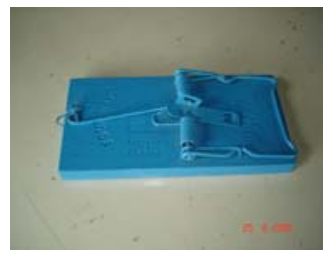

Fig. 5 = Wooden snap trap

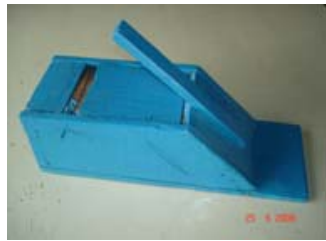

Fig. $3=$ Wooden live trap 


\section{Result And Discussion}

\section{Rat species composition}

During the grain filling stage 271 animals were captured by trapping. Out of them $234(86.35 \%)$ were rodents and $37(13.65 \%)$ were shrew (Table 1). Among the rodents, 229(97.86\%) were Bandicota bengalensis and only $5(2.14 \%)$ were Mus terricolor. In the ripening stage, 185 animals were trapped of which $164(88.65 \%)$ were rats and $21(11.35 \%)$ were shrew. All captured rats were Bandicota bengalensis. It is obvious that Bandicota bengalensis was the dominant rat species in the wheat field and Mus terricolor was present at low population densities. Roy et al. (1987) found Bandicota bengalensis as a dominant species in the poultry farm of Monipur, India. Bandicota bengalensis is also the dominant species in deep water rice fields (Islam and Karim 1995; Catling and Islam 1999). There was higher rat activity (population) at grain filling stage than at the ripening stage, which is consistent with farmers' perception of higher rat damage at the booting to grain filling stage than at the ripening stage of wheat crop.

Table 1. Rats and other animals trapped in the wheat fields during booting to ripening stage of the 2007-08 wheat seasons using bread, dry fish, paddy grain, coconut and potato as bait material, Dinajpur, Bangladesh

\begin{tabular}{lccccc}
\hline \multirow{2}{*}{ Attributes } & \multicolumn{2}{c}{ Crop growth stage } & \multirow{2}{*}{ Total } & \multirow{2}{*}{ Percentage } \\
\cline { 2 - 3 } & Grain filling & Ripening & & \\
Trap nights & 990 & 810 & & \\
Animal trapped (Total number) & & & 393 & 86.18 \\
$\quad$ Rats - Bandicota bengalensis & 229 & 164 & 5 & 1.10 \\
$\quad-$ Mus terricolor & 5 & - & 58 & 12.72 \\
$\quad$ Shrews - Suncus murinus & 37 & 21 & 456 & 100 \\
\hline Total & 271 & 185 & & \\
\hline
\end{tabular}

\section{Trap efficiency}

The rodent capture efficacy of different kinds of traps was varied significantly in both growth stage of wheat crop. During the grain filling stage, trap success for cage type live trap, box type live trap, wooden live trap, tin made snap trap and wooden snap trap was $41.92 \%, 9.09 \%, 14.14 \%, 31.82 \%$ and $21.21 \%$, respectively (Table 2 ). Cage type live trap showed the highest trap success $(41.92 \pm$ $1.82 \%)$ which is followed by tin made snap trap (31.82 $\pm 2.62 \%)$. They were statistically similar. Moderate success in trapping rodents was achieved by setting wooden snap trap $(21.21 \pm 3.15 \%)$ which is statistically similar with that of tin made snap trap. Only $14.14 \pm 3.53$ per cent trap success was found in case of wooden live trap but it was statistically similar with box type live trap (9.09 \pm $0.88 \%)$. In the ripening stage of wheat, the trap success of cage type live trap, box type live trap, wooden live trap, tin made snap trap and wooden snap trap was $46.30 \%, 11.73 \%, 5.56 \%, 29.63 \%$ and $8.03 \%$ respectively. Cage type live trap showed the highest trap success $(46.30 \pm 2.14 \%)$. Moderate trap success was found in case of tin made snap trap $(29.63 \pm 2.14 \%)$. Only $11.73 \pm$ 1.63 per cent trap success was found in case of box type live trap which is statistically similar with that of wooden snap trap $(8.03 \pm 1.63 \%)$ and wooden live trap $(5.56 \pm 1.07 \%)$. Over the two growth stage of wheat, the rat capturing eficiency was highest in case of cage type live trap $(44.11 \%)$ and the second highest was tin made snap trap (30.73\%). Alam et al. (2007) found live trap more effective than kill trap for trapping rodents in the poultry farms of Gazipur district, Bangladesh. The ineffective sprung rate was higher in case of wooden snap trap. The activity of civet was highly observed in the wheat field. Their movement could be a factor for more ineffective sprung of wooden kill trap due to it's over sensitivity. It may be a cause for the moderate to lower success of wooden kill trap. 
A. T. M. Hasanuzzaman et al.

Table-2. Rat capturing efficiency of five different types of traps during different growth stages of wheat

\begin{tabular}{lcc}
\hline \multicolumn{1}{c}{ Trap type } & \multicolumn{2}{c}{$\%$ Trap success (mean \pm SE) } \\
\cline { 2 - 3 } & Grain filling stage & Ripening stage ${ }^{\star *}$ \\
\hline Cage type live trap made by iron net & $41.92 \pm 1.82 \mathrm{a}$ & $46.30 \pm 2.14 \mathrm{a}$ \\
Box type live trap made by tin & $9.09 \pm 0.88 \mathrm{~d}$ & $11.73 \pm 1.63 \mathrm{c}$ \\
Wooden live trap & $14.14 \pm 3.53 \mathrm{~cd}$ & $5.56 \pm 1.07 \mathrm{c}$ \\
Tin made snap trap & $31.82 \pm 2.62 \mathrm{ab}$ & $29.63 \pm 2.14 \mathrm{~b}$ \\
Wooden snap trap & $21.21 \pm 3.15 \mathrm{bc}$ & $8.03 \pm 1.63 \mathrm{c}$ \\
\hline
\end{tabular}

* Average of three places, 66 trap night per place.

${ }^{* *}$ Average of three places, 54 trap night per place.

Mean followed by same letter do not differ significantly at $1 \%$ level of significance (LSD).

\section{Bait preference}

In both the grain filling and ripening stage of wheat, the number of rats ( $B$. bengalensis) caught in the trap with different bait was differed significantly (Table-3). In grain filling stage, paddy grain as bait showed the highest trap success $(37.58 \pm 6.15 \%)$ which was followed by bread $(27.00 \pm 4.51$ $\%)$. Dry fish and coconut as bait materials showed $23.64 \pm 7.92$ and $19.45 \pm 4.34$ per cent trap success, respectively. Only $6.67 \pm 1.67$ per cent trap success was found in case of potato bait. But in ripening stage of wheat, the highest trap success was found in case of bread as bait $(24.76 \pm$ $4.54 \%)$. Dry fish bait $(24.58 \pm 3.63 \%)$ showed the similar result which was followed by paddy grain $(21.67 \pm 3.63 \%)$. Coconut and potato bait showed only $11.67 \pm 3.01$ and $10.83 \pm 0.83$ per cent trap success, respectively. Over the two growth stage of wheat, $29.63 \%, 25.88 \%, 24.11 \%, 15.56 \%$ and $8.75 \%$ trap success was found in case of paddy grain, bread, dry fish, coconut and potato bait, respectively. Similar findings were reported by Kamal \& Hossain (2003), where paddy grain was the bait which most preferred by rat in rice field, while dry fish and coconut was the second and third preferred bait, respectively. Alam et al. (2007) evaluated six different baits for trapping rodents in the poultry farms. Among the 6 different bait types the preferred order was dry fish, coconut meat, potato, bread, soap and wax.

Table-3. Bait preference of Bandicota bengalensis during at grain filling and ripening stage of wheat crop

\begin{tabular}{lllll}
\hline Bait used & \multicolumn{2}{c}{ Grain filling stage } & \multicolumn{2}{c}{ Ripening stage } \\
\hline & Trap night & $\begin{array}{l}\text { \% trap success } \\
\text { (mean } \pm \text { SE) }\end{array}$ & Trap night & $\begin{array}{l}\% \text { trap success } \\
(\text { mean } \pm \text { SE) }\end{array}$ \\
\hline Bread & 300 & $27.00 \pm 4.51$ & 210 & $24.76 \pm 4.54$ \\
Potato & 180 & $6.67 \pm 1.67$ & 120 & $10.83 \pm 0.83$ \\
Coconut meat & 180 & $19.45 \pm 4.34$ & 120 & $11.67 \pm 3.01$ \\
Dry fish & 165 & $23.64 \pm 7.92$ & 240 & $24.58 \pm 3.63$ \\
Paddy grain & 165 & $37.58 \pm 6.15$ & 120 & $21.67 \pm 3.63$ \\
\hline$X^{2}$-value & - & 50.731 & - & 17.652 \\
Level of significance & - & 0.01 & - & 0.01 \\
\hline
\end{tabular}

${ }^{*}$ Average of three places.

\section{CONCLUSION}

Bandicota bengalensis was the most common species in study area. This species had a descending order of preference of bait as: paddy grain, bread and dry fish in the wheat field. Trapping is environment friendly and ecologically sound method for controlling rodent. Considering the trap success, availability in the local market and cost of the traps it can be concluded that farmer can use cage type live trap and tin made snap trap for controlling rodents in the wheat fields with paddy grain and bread as bait. 
Comparative efficiency of different traps to capture rats in the wheat field

\section{LITERATURE CITED}

Ahmad, N., 1986. Studies on rodent pest management in agro and forest ecosystems. Unpublished $\mathrm{PhD}$ thesis, Garhwal University, Srinagar.

Ahmed, E., Hussain, I. and Brooks, J.E. 1995. Losses of stored foods due to rats at grain markets in Pakistan. International Biodeterioration and Biodegration. 36, 125-133.

Ahmed, M.S., Mian, M.Y., Haque, M. E. \& Brooks, J.E. 1986. Estimating rat damage in deep water rice. Int. Rice Res. Newsl,. 11(1), 23-4.

Alam, M.S., Mian, M.Y. and Hasanuzzaman, A.T.M. 2007. Evaluation of different bait materials for trapping rodents. Bangladesh J. Agric. and Environ. 3(2), 31-36.

Bindra, O. S. and Sagar, P. 1968. Study on the losses to wheat, groundnut and sugarcane crops by the field rats in Punjab. Proceedings of the International Symposium on Bionomics and Control of Rodents, pp.28-31.Kanpur, India.

Buckle, A.P. 1999. Rodenticides-their role in rodent pest management in tropical agriculture. In: Singleton, G.R., Hinds, L.A., Leirs, H. and Zhang, Z., ed., Ecologically-based management of rodent pests. ACIAR Monograph No. 59, Canberra, Australian Centre for International Agricultural Research, 163-177.

Catling, H.D. and Z. Islam. 1999. Pest of deep water rice and their management. Integrated Pest Management Review. 4, 193-229.

Gebauer, U., Dubbel, V. and Friedrich, E. 1992. Control of small rodent pests with spring traps. Allgemeine Forst Zeitschrift, 47, 408-409

Islam, Z and Karim, A.N.M.R. 1995. Rat control by trapping in deepwater rice. International Journal of Pest Management, 41, 229-233.

Kamal, N.Q. and Hossain, M.M. 2003. Comparison of different baits to attract rats to traps in rice fields in Bangladesh. In: Singleton, G.R., Hinds, L. A., Krebs, C. J. and Spratt, D. M. (eds), 2003. Rats, Mice and People: Rodent biology and management. ACIAR Monograph No. 96, Canberra, Australia. 281-283p.

Parrack, D.W. 1969. A note on the loss of food to the lesser bandicoot rat, Bandicota bengalensis. Curr. sci.38, 93-94.

Roy, L.G., Singh, R.K.T. and Singh, K.D. 1987. Rodent control in Poultry farm near Imphal, Monipur, India, using Bromadiolne. Rodent Newsletter. 11(1-4), 8.

Roy, S.K. 1974. Pre-harvest loss of rice due to field rodents, Economics and political weekly.9, 6667.

Singleton, G.R., Hinds, L., Leirs, H. and Zhang, Z. (eds). 1999. Ecologically-based Rodent Management. ACIAR Monograph series \# 59. Canberra: Australian Centre for International Agricultural Research. p 494.

Sood, M. L. and Guraya, S.S. 1976. Rats and Their Control. Punjab Agricultural University, Ludhiana: press Publication.

Tobin, M.E., Koehler, A.E., Sugihara, R.T., Ueunten, G.R. and Yamaguchi, A.M. 1993. Effect of trapping on rat populations and subsequent damage and yield of macadamia nuts. Crop Protection. 12, 243-248.

Wang, C.X. 1996. Rodent control and public health. In: Wang, Z.W. and Zhang, Z.B., ed., Theory practice of rodent pest management. Beijing, Science Press, 38-52 (in Chinese, with English abstract). 